\title{
Pathological changes in virus infections of the lower respiratory tract in children
}

\author{
W. AHERNE, T. BIRD, S. D. M. COURT, P. S. GARDNER, AND \\ JOYCE McQUILLIN \\ From the Departments of Pathology, Virology, and Child Health in the University, the Royal \\ Victoria Infirmary, the General Hospital, and the Institute of Pathology, Newcastle upon Tyne
}

SYNOPSIS The pathological changes are described in 22 children with proven or suspected $\overrightarrow{\mathbb{T}}$ virus infection of the lower respiratory tract. Two main patterns of disease were found: acute을 bronchiolitis and interstitial pneumonia. Particular viruses were not specifically associated@ with particular histological changes. The prime importance of the respiratory syncytial virus (RSV) as a cause of disease and death in young infants is again shown. Structural lesions and $\stackrel{\ominus}{\ominus}$ clinical dysfunction correlate fairly well; in acute bronchiolitis the main lesion is epithelial ${ }^{\circ}$ necrosis when a dense plug is formed in the bronchiolar lumen leading to trapping air and other mechanical interference with ventilation: in interstitial pneumonia there is widespread inflammation and necrosis of lung parenchyma, and severe lesions of the bronchial and $\mathrm{D}_{\bar{D}}^{\mathscr{Q}}$ bronchiolar mucosa as well. The implications of these structural changes for clinical manage- $\stackrel{\AA}{\varrho}$ ment are discussed. The possibility of a hypersensitivity reaction in the cot death syndrome $\overrightarrow{\vec{O}}$ is raised, mediated by a serum antibody-antigen-complement reaction.

In 1967 3,000 children died in England and Wales from infection of the respiratory tract. They accounted for $27 \%$ of all deaths in children between the ages of 1 month and 15 years. Seventy-five per cent were infants under the age of 1 year, and $46 \%$ died at home (General Register Office, 1967, and personal communication). The corresponding figures for our community, the northern region of England, were 204 deaths of which $80 \%$ were infants. In Newcastle, of every 100 acute infective illnesses in the first five years of life, 60 affect the respiratory tract, and 17 are either bronchitis, bronchiolitis, or pneumonia. A large and challenging task, therefore, still faces those concerned with the clinical management of these illnesses and a clearer understanding of their aetiology and pathogenesis is urgently needed.

Except in proven bacterial infections aetiology Received for publication 29 October 1969. has remained obscure. But in recent years the part played by virus infection, and the outstanding importance of respiratory syncytial virus (RSV) as a cause of severe respiratory disease and death in children, has been established (Beem, Wright, Hamre, Egerer, and Oehme, 1960; Chanock, N Kim, Vargosko, Deleva, Johnson, Cumming, $\omega$ and Parrott, 1961; Holzel, Parker, Patterson, White, Thompson, and Tobin, 1963; Andrew and Gardner, 1963; Crone, Heycock, Noble, and Patton, 1964; Elderkin, Gardner, Turk, and ${ }^{+}$ White, 1965).

For the past 10 years we have been engaged in a continuing survey of acute respiratory diseases? in childhood in the Newcastle area. The purpose $\odot$ of this paper is to describe and relate the morphological and virological features of 22 fatal lowero respiratory tract infections. The clinical aspects응 have already been published (Gardner, Turk Aherne, Bird, Holdaway, and Court, 1967). 
W. Aherne, T. Bird, S. D. M. Court, P. S. Gardner, and Joyce McQuillin

Six children in that series died with bacterial infection and, as this is not our concern here, they have been omitted from the present paper. Six other children are included; four who failed on clinical grounds to qualify for admission to the earlier series, and two who presented since the previous report was published.

We begin with a composite review of the lower respiratory tract pathology, based on our own observations and on descriptions in the literature. When this was related to the virus investigations in the 22 children four main categories emerged: the morphological patterns of disease in each of these are described. Finally, we consider the increase in clinical understanding which can come from a study of this kind.

\section{Methods}

VIROLOGICAL TECHNIQUES

Lung tissue for virus isolation was collected at necropsy, in many cases up to or longer than 48 hours after death. The tissue was homogenized in 10 times its own volume of medium 199 and then lightly centrifuged; the supernatant fluid was used for inoculating tissue cultures. The cell lines used for culture of the lung tissue were Bristol HeLa, $\mathrm{HE}_{\mathrm{p}} 2$, rhesus monkey kidney, and human diploid cells (W.I. 38).

In the two most recent patients an indirect fluorescent antibody technique was applied to touch preparations made from freshly cut lung surface and to frozen cryostat sections. The technique for fluorescent staining was essentially that described by Gardner and McQuillin (1968) for the detection of respiratory syncytial virus. Formalin-fixed sections from earlier cases were also examined in this way but the results were unsatisfactory and will not be discussed.

Swabs from seared surfaces and/or pieces of lung were taken for bacteriological examination. The series was defined mainly by the negative results of these examinations.

\section{PATHOLOGICAL TECHNIQUES}

Blocks were taken from both lungs in each case. In the more recent cases one lung was inflated with Heidenhain's Susa fixative and samples were taken from the contralateral lung for virological examination. In most cases, however, virological samples were taken from both lungs and inflation with fixative was therefore precluded. The tissue was fixed in Susa or $10 \%$ formol-saline solution and processed in the usual way. Sections were stained by haematoxylin and eosin in all cases, and by the phloxine-methylene blue, periodic-acid-Schiff, acid-picro-Mallory, and Gram techniques, where these seemed appropriate.
Review of Relevant Lower Respiratory Pathology

The conditions encountered in this study ape well known but it seems worthwhile to reviegw their distinguishing features because the type of dysfunction, and perhaps the mode of treztment, will depend on the type of disordered morphology present. The main diseases fou were (a) acute bronchiolitis and (b) pneumon both interstitial and intra-alveolar. A brgef comment will be made also on five children who died suddenly and unexpectedly (cot death syndrome). Their inclusion does not necessarify imply that we regard them as deaths from respiratory infections in the ordinary sense $\overrightarrow{\text { ogf }}$ this term.

\section{ACUTE BRONCHIOLITIS}

This inflammation typically affects bronchioies of which the calibre ranges from $300 \mu$ down $\$$ about $75 \mu$. The pathological changes were first clarified by Hubble and Osborne (1941), who established acute bronchiolitis as a distiret entity in children. They concluded that the earliest lesion, occurring 18 to 24 hours after the onset of the disease, is necrosis of the bronchio epithelium, followed in due course by perfbronchiolar 'round cell', ie, lymphocytic infftration. Their findings were confirmed akd greatly extended by McLean (1956) who obtaingod some 20,000 sections from the lungs of 70 pestients, and in 27 selected blocks studied 400 \&o 1,200 serial sections in detail.

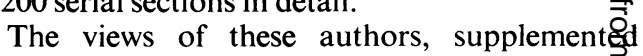
by our own observations, may be summarized as follows.

The bronchiolar epithelium is colonized virus which then replicates, and necrosis of the epithelium, or occasionally proliferation, follow. Destruction of ciliated epithelial cells removess an important local defence mechanism. The host tissues respond by mobilizing a peribronchiōlar infiltrate of lymphocytes with some plasna cells and macrophages. Lymphocytes are fre quently seen among the mucosal epithelial cells, presumably having migrated from the peribronchiolar accumulations. The submucosa and adventitial tissues become oedematous ared congested, but typically there is no damage to elastic fibres or muscle. Secretion of muce is enhanced, and thick plugs form in the bronchiolar lumina composed of cell debris, strands of fibrin, and a material with the staining properties of DNA.

These dense plugs, which occlude the smaller. bronchioles, are clearly a most importa@t feature of acute bronchiolitis. Hubble arf Osborne quote Jackson (1934) who drew attegtion to four types of bronchiolar obstruction which the plug may cause:- (1) A bypass vale mechanism, in which both the ingress and egress of air is checked but not completely obstructeg? 
This type of lesion limits ventilation but does not of itself give collapse or emphysema. (2) A check valve mechanism which permits ingress of air but prevents egress and thereby leads to air trapping and acute obstructive emphysema. (3) A stop-valve mechanism by which the bronchiole is completely obstructed, leading to collapse of the lobule which that bronchiole supplies. (4) A ball valve mechanism which allows only the egress of air and leads to a more rapid lobular collapse than the stop-valve process.

Depending therefore on the degree and the extent of plug formation the patient may present with acute emphysematous air trapping, or lobular collapse, or both. The infant lung is particularly prone to these mechanical lesions because of the small calibre of the bronchioles and the very poor collateral ventilation from neighbouring alveoli. There is experimental evidence (quoted by McLean, 1956) that with good collateral ventilation a sufficiently high pressure may build up distal to an occluding plug which eventually leads to its expulsion. This appears not to happen in the infant lung.

During recovery from acute bronchiolitis the bronchiolar epithelium regenerates from the basal layer in three to four days but cilia rarely appear before the fifteenth day. Mucus plugs are eventually removed by muciphages. As the specialized elastic and muscular tissues have not been damaged the bronchial tree should recover its integrity completely.

\section{PNEUMONIA}

In pneumonia the inflammatory exudate may appear primarily in the parenchymal air spaces and the lumina of the smaller conducting airways, or in the interstitial tissues which separate these spaces from each other, or both. Interstitial inflammation is more usual in virus infection of the lung.

The type of pneumonia which mainly involves the parenchymal air spaces appeared only once in the present series. For this reason, and because its morphology is well known, it will not be described in detail. It is usually bacterial and the exudate is characterized by polymorphs. In our single case no bacterium was isolated, but RSV was; and the exudate was predominantly mononuclear.

The interstitial pneumonias we observed were broadly of two kinds: one was essentially that described by Morison (1955) and the other that described by Becroft (1967). The views of these authors, again supplemented by our own observations, may be summarized as follows.

In pneumonia of the first kind (Morison, 1955) the normal ciliated epithelium of bronchi and bronchioles becomes cuboidal or flat and the cilia are lost. The subepithelial tissues of bronchi and bronchioles, and the interalveolar walls thicken due to a mononuclear cell infil- tration. The detailed structure of the alveolar walls may be difficult to sort out but the main impression is that they are hypercellular. This, of 0 course, is due to the inflammatory lymphoid infiltration. Alveolar lining cells may become more prominent and the alveolar spaces usually contain oedema fluid. The severity of these changes may vary widely from one region to another.

Pneumonia of the second kind (Becroft, 1967) is more severe. Indeed, the term 'pneumonia' is somewhat misleading here because profound o lesions occur also in the bronchial tree.

It appears very likely that the virus again infects the bronchial and bronchiolar epithelium and probably alveolar lining cells as well. Our evidence for this is based on fluorescent antibody staining but is still somewhat meagre; much w more work is needed on this topic. A variety of bronchial and bronchiolar epithelial changes may be seen: hyperplasia of abnormal, poorly differentiated cells, severe epithelial necrosis, denudation. Often the remains of the bronchial epithelium can be seen in the lumen as an eosinophilic slough. In some fields layers of stratified, undifferentiated epithelium or large, elongated, single cells may be present, in both instances showing cytoplasmic basophilia and mitotic activity. These are presumably regenerating epithelia.

The greatest inflammatory response, comprising lymphocytes, macrophages, and some plasma cells, is sited around the smaller bronchioles and extends into the tissues of their associated alveoli. Throughout the parenchyma foci of total necrosis occur, usually centred on denuded bronchiole. This suggests centrifugal spread of virus particles to alveoli after replication in the bronchiolar epithelium. The necrotic material contains a dust of finely fragmented cell nuclei; the intact inflammatory cells are mononuclear.

The alveolar parenchyma between foci of necrosis is oedematous and evidently not aerated. Many alveoli are lined by thick hyaline membranes or show swollen alveolar lining cells. Overstretched, acutely emphysematous lobules, so commonly a feature of acute bronchiolitis, are rare. Interlobular and perivascular connective tissues may be extremely oedematous with distended lymph vessels containing an eosinophilic fluid.

\section{COT DEATH SYNDROME}

The meagre necropsy findings in the cot death syndrome comprise pulmonary oedema, often severe, and occasional aspiration of gastric material.

\section{SUMMARY}

Acute bronchiolitis is characterized by bronchiolar epithelial damage and occlusion of อ

\section{,}


bronchiolar lumina, leading to mechanical deformations of the pulmonary parenchyma; pneumonia by bronchial and bronchiolar damage, without much occlusion of lumina but with severe inflammation and focal necrosis of lung parenchyma; and cot death by pulmonary oedema.

\section{Virological Findings and Related Pathology}

The separation into four categories according to the virological findings and the pathological entities found in each category were as follows.

\section{RESPIRATORY SYNCYTIAL VIRUS (RSV) RECOVERED FROM LUNG TISSUE AT NECROPSY}

Of the 12 patients in this category the lungs of five (cases 1, 2, 3, 4, and 5) showed the histological changes of acute bronchiolitis as described above. An early stage, uncommonly seen, is illustrated in Figure 1. At later stages, represented by the other four cases, epithelium of an undifferentiated pleomorphic kind was present, varying in thickness and occasionally showing mitotic activity (Fig. 2). It is not clear whether this epithelium was proliferating in response to virus or regenerating after necrosis. The usual (though not invariable) absence of inclusion bodies from it is evidence for regeneration. Inclusion bodies were found most often in epithelium which was breaking up (Fig. 3): in general, they were difficult to find. Occasionally, elongated basophilic cells were seen spreading over recently denuded lamina propria (Fig. 4). These we did interpret as regenerating epithelium. Figure 5 shows a touch preparation made from the cut surface of a lung of case 5 , stained by the fluorescent antibody technique for RSV. The distribution of these cells was scanty, as one might expect from the patchiness of the histological changes in this early acute bronchiolitis. The bronchiolar plug, characteristic of the later stages, and the typical peribronchiolar lymphoid infiltration are shown in Figures 6 and 7 respectively. Subsegments of collapse (Fig. 8) were commonly due to blockage of bronchioli. Overdistension of lobules (obstructive emphysema) due to partial bronchiolar occlusion was also present but its true severity was difficult to assess: distended lobules probably deflated during or after death. Alveoli generally were not involved in the inflammatory process, except now and then those immediately surrounding an affected bronchiole. One child, however, who suffered primarily from acute bronchiolitis, had foci of alveolar involvement (Fig. 9) which suggested a histological transition to the changes of interstitial pneumonia.

The hilar lymph nodes showed only a moderate reactive hyperplasia.
Four children succumbed to pneumoni를 One of these was an example of intraalveolat pneumonia, in which there was a diffuse inflam matory exudate in the air spaces, with main mononuclear cells and a few polymorphs (Fig. 10). Two children had interstitial pneumon as described by Morison (1955) with minima tissue destruction; in one of these the pneumone was mild and probably precipitated heart failuze primarily due to endocardial fibroelastosis. The remaining child (case 6) had a florid pneumoni of the kind described by Becroft (1967) wifh widespread destruction of bronchial and brop chiolar epithelium (Fig. 11), parenchymal necrosis (Fig 12), and extensive interstitial infiltratiogs by lymphoid cells. There were thrombi several fairly large muscular pulmonary arteris (Fig. 13). Oedema, both of air spaces (associated often with hyaline membranes, Fig. 11) and of interstitial tissues (Fig. 11) was severe. Figure 14 shows a touch preparation made from this child's lung, again stained by the fluorescent antibody technique for respiratory syncyti virus. Specifically fluorescent cells were abundan in marked contrast to their scantiness in bronchi litis, but the cytoplasmic position of the fluorese्t ing particles is the same.

The three remaining fatalities in this class were cot deaths. One child showed occasional pero bronchial lymphocytic infiltration but there were no atypical epithelial cells. All showed severe pulmonary oedema. The significange of recovering RSV from these children and is possible relation to their deaths remains matter for further study.

2 VIRUS OTHER THAN RESPIRATORY SYNCYTIAL VIRUS RECOVERED FROM LUNG TISSUE AT NECROPSY

The one child in this class (case 13) yielded adenovirus type 1 . The histological changes which were those of a severe and widespreag interstitial pneumonia closely resembled those of case 6 above. They consisted mainly of foct necrosis, interstitial inflammatory infiltration. and oedema, and necrosis of bronchiolar ans alveolar epithelium with the formation of thicks fibrinous 'hyaline membranes' in the alveolat ducts. As in case 6, large thrombi were occasiont ally present in the muscular pulmonary arterioles.

3 VIRUS RECOVERED FROM THE UPPER RESPIRATORY TRACT BEFORE DEATH BUT NOT FROM THE LUNG TISSUE AT NECROPSY

Of the two children in this category one yieldee respiratory syncytial virus from the throat, but lung tissue was not cultured at necropsy. The histological changes were mild and consistea mainly of a lymphoid infiltration of bronchis. walls, with a little epithelial necrosis and en 


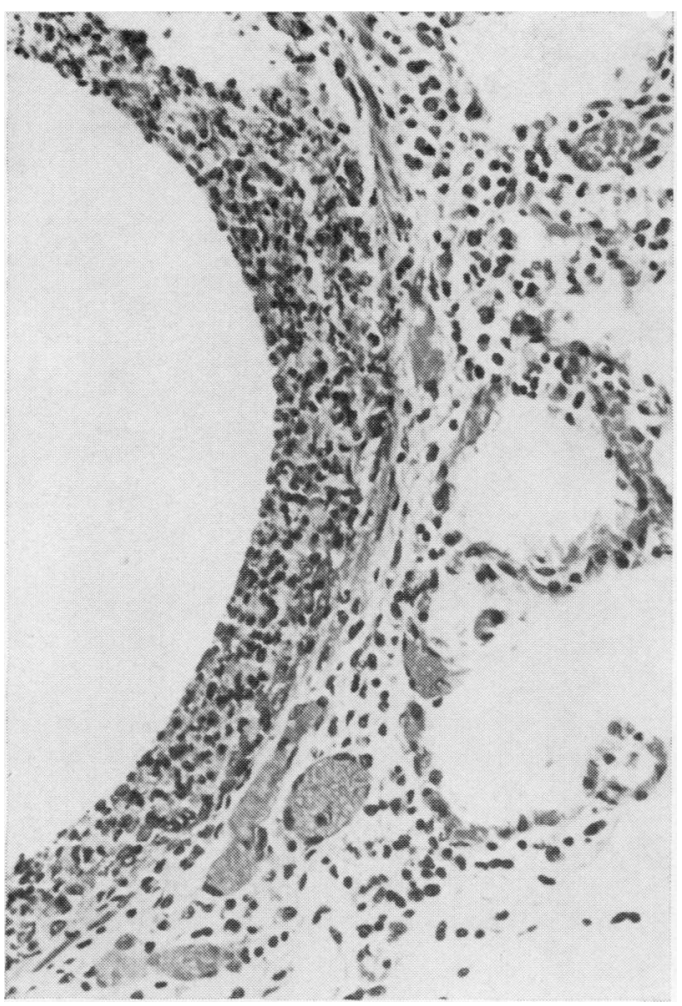

Fig. 1 Complete destruction of bronchiolar epithelium, with minimal peribronchiolar cellular response. Acute bronchiolitis, early stage.

Haematoxylin and eosin $\times 150$.

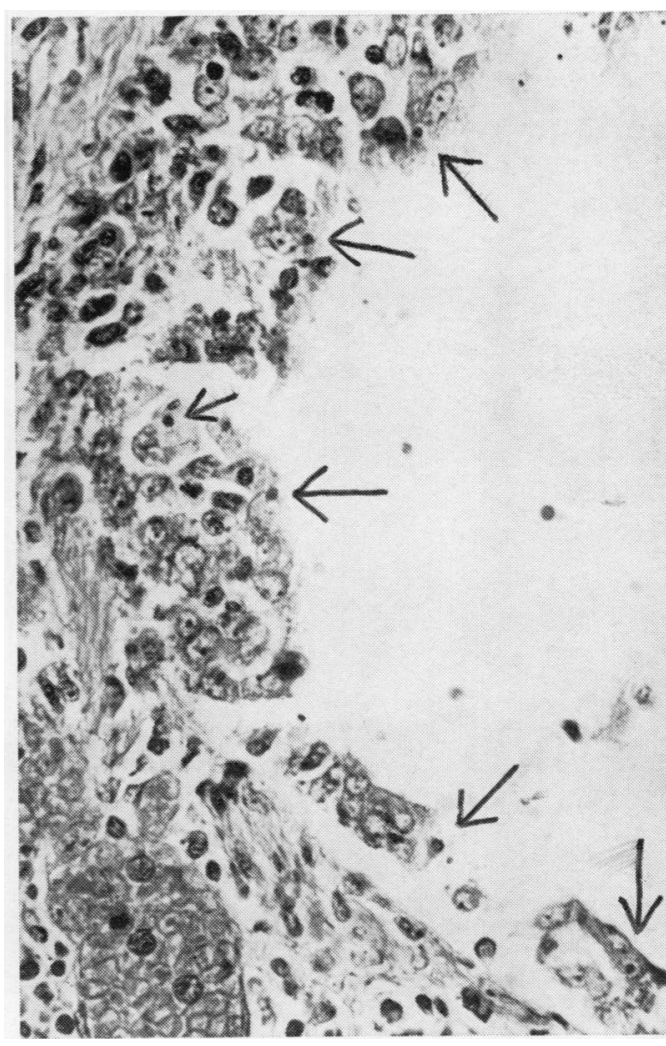

Fig. 3 Pre-necrotic bronchiolar epithelium, containing several cytoplasmic inclusion bodies (arrowed). Acute bronchiolitis. Phloxine-methylene blue $\times 375$.

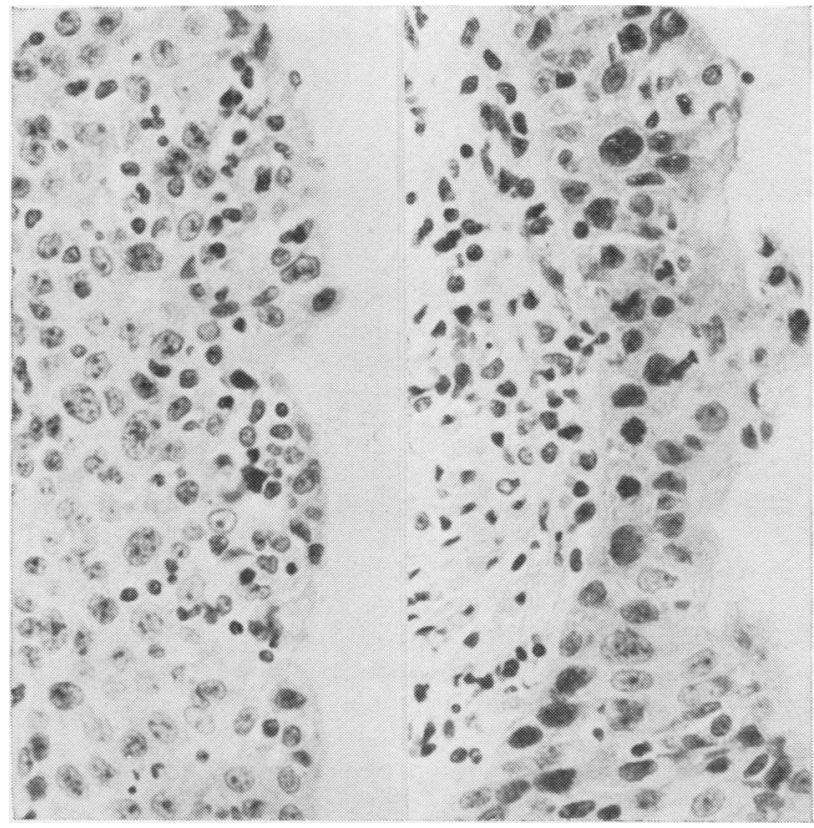

Fig. 2 Pleomorphic epithelium lining small bronchioles (composite photograph); hyperplasia? due to viral stimulation, ? regeneration. Haematoxylin and eosin $\times 250$. 


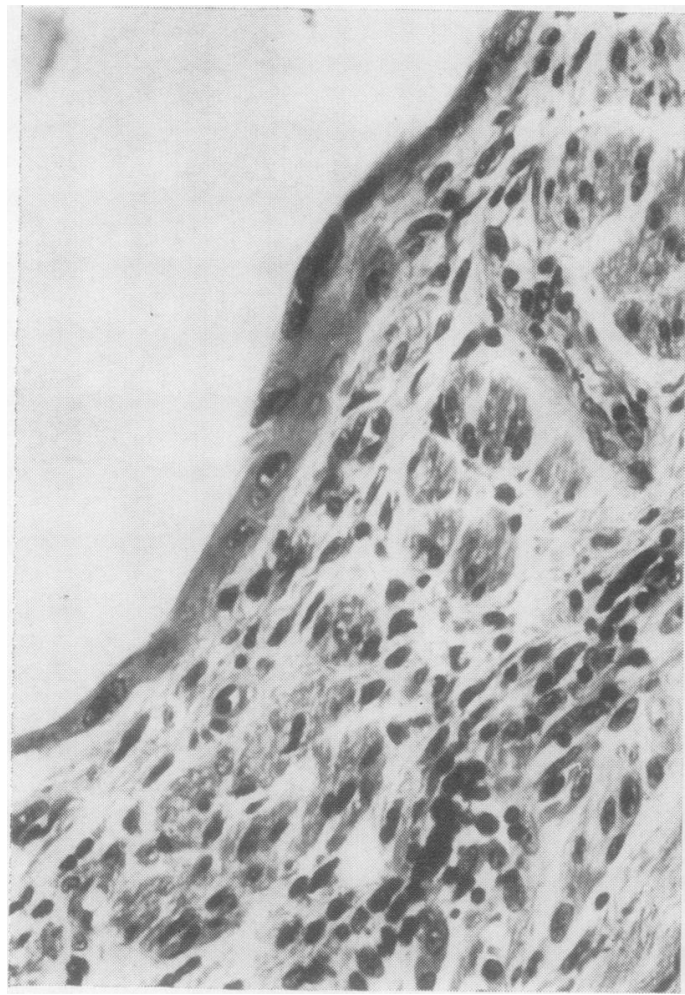

Fig. 4 Long, basophilic cells, interpreted as regenerating bronchiolar epithelium. Acute bronchiolitis. H.E. $\times 250$.

hanced mucus gland activity. This child had Down's syndrome, and the respiratory infection probably precipitated heart failure primarily due to a large atrial (ostium secundum) septal defect.

The second patient (case 15) yielded parainfluenza virus type III from the throat. At necropsy an interstitial pneumonia was found similar in kind to that found in cases 6 and 13 but less severe.

\section{NO INFECTIVE AGENT OF ANY KIND RECOVERED}

There were seven patients in this category. Two (cases 16 and 17) were examples of acute bronchiolitis, with epithelial atypia, heavy lymphoid infiltration, and obstruction of the bronchiolar

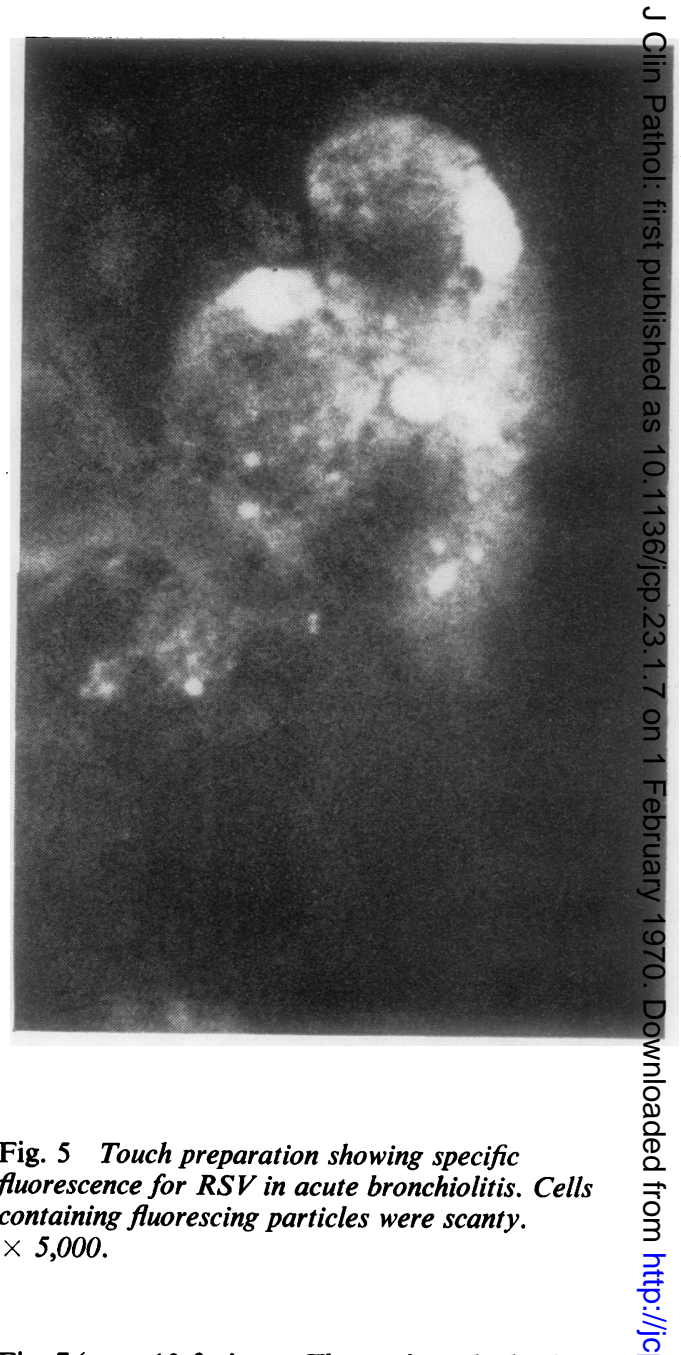

Fig. 7 (page 13 facing) The peribronchiolar lympho infiltration in acute bronchiolitis. Note also the epithelial irregularity. Surrounding alveoli contain a iittle exudate only. H.E. $\times 60$.

lumen, very similar to the first five patients of class 1 . It seems probable that the virology from these patients was falsely negative. In one the inflammatory process had extended into the contiguous alveoli, making a bronchopneumonte pattern. Two further patients (cases 18 and 19 had the topographical changes of acute bronchios litis but differed from the preceding cases in that the infiltrating cells were predominantly neutrophil polymorphs and the atypical epithelia伭 changes were not seen. Again, bronchopneumoni $\Phi_{0}^{+}$ extension was evident in one (case 19). Another child (case 20) had a mild bronchiolitis but death was attributable to sagittal sinus throm8 bosis.

The remaining two children died suddenlo and unexpectedly (cot death syndrome). 


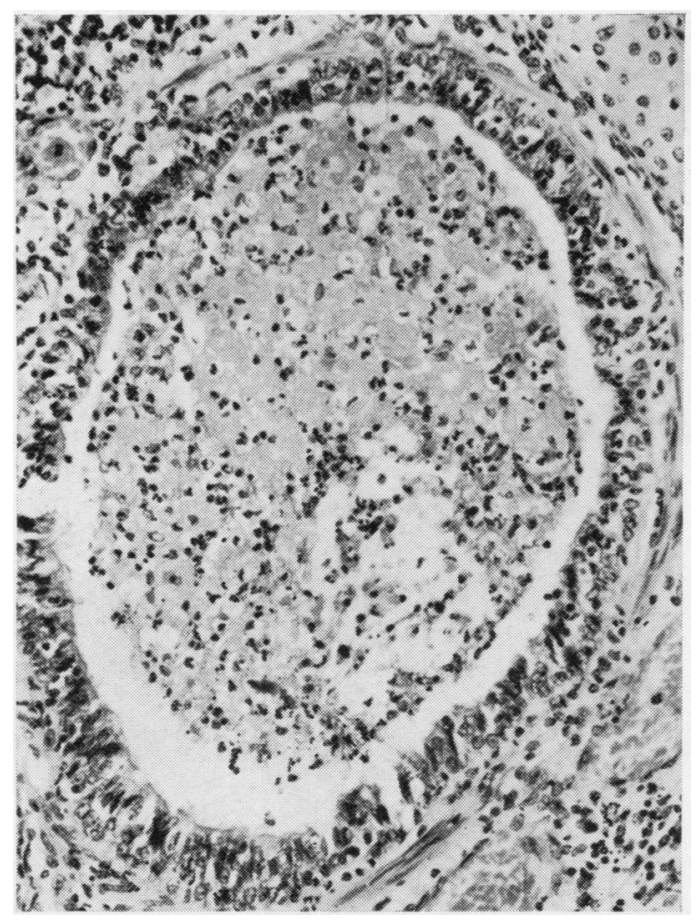

Fig. 6 The plug of exudate, mucus, and cell debris. The rim of patency is a shrinkage artefact; occlusion of this small bronchus may have been complete. Note epithelial abnormality and transmigrating lymphocytes. Acute bronchiolitis. H.E. $\times 120$.

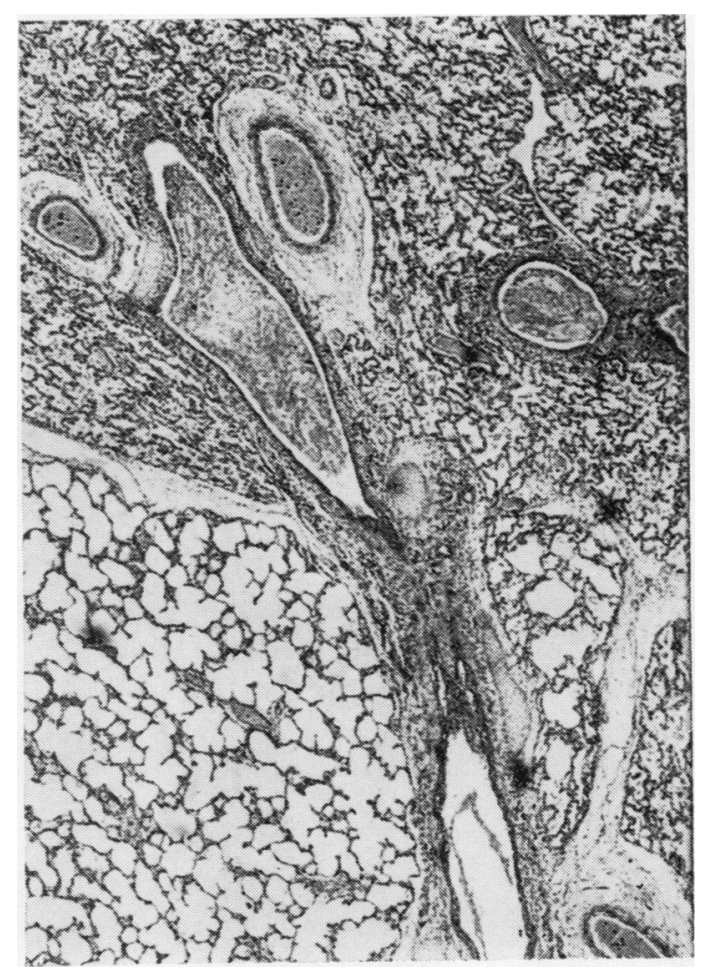

Fig. 8 Collapse of alveoli due to blockage of the supplying bronchiole. Note plugs of exudate, mucus, and cell debris. Acute bronchiolitis. H.E. $\times 30$.

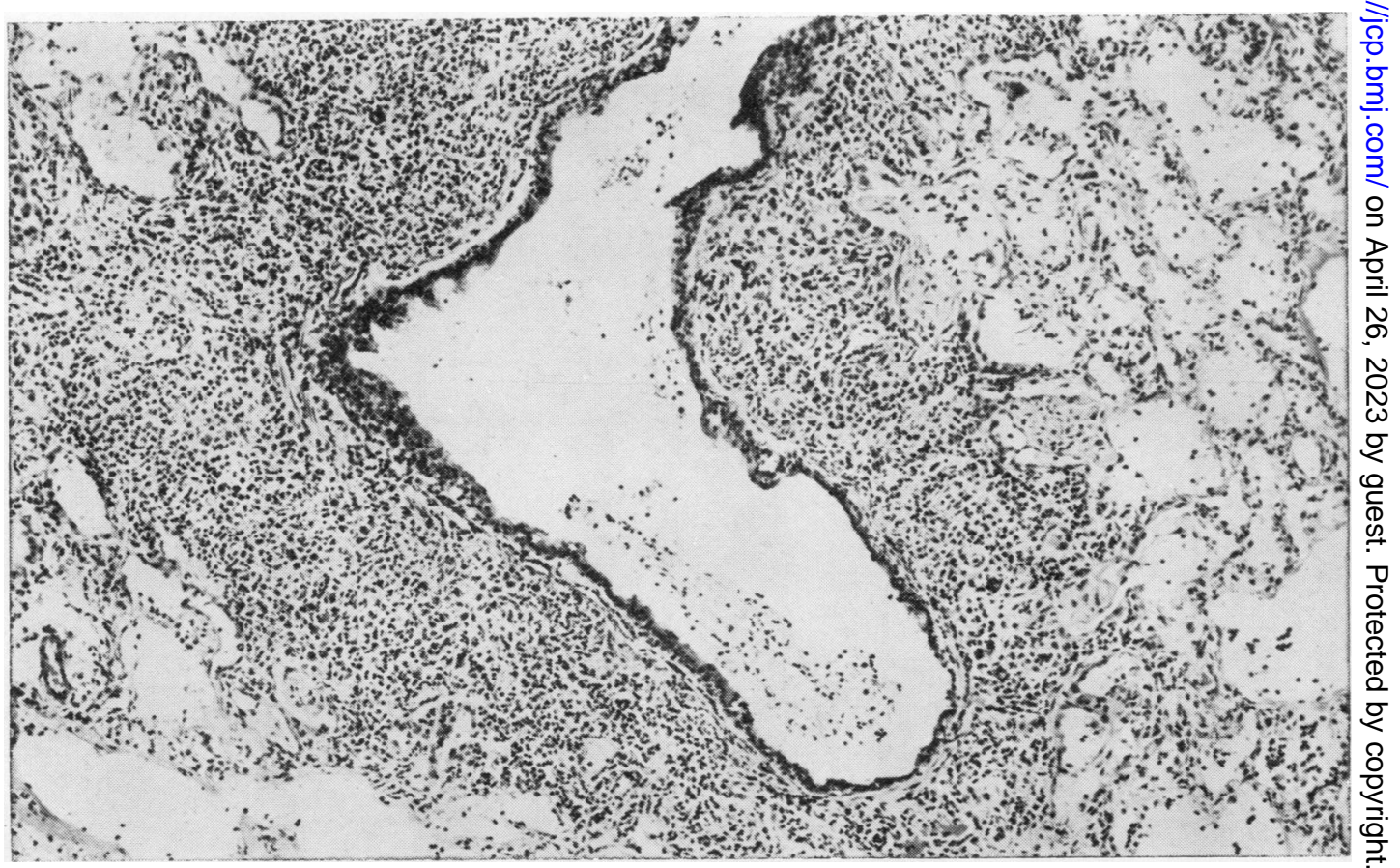




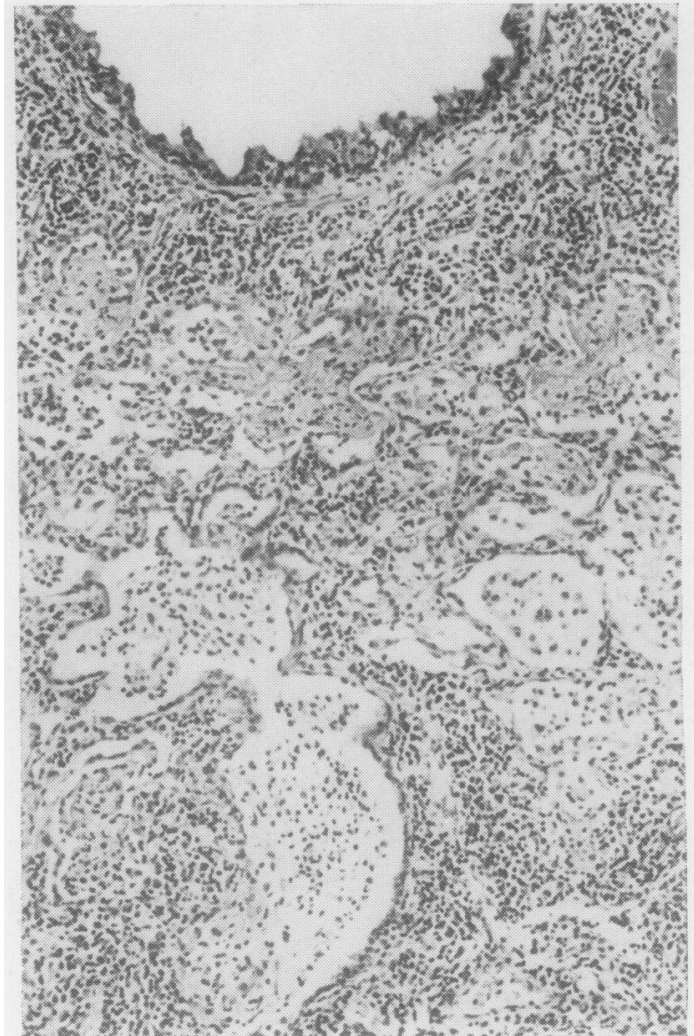

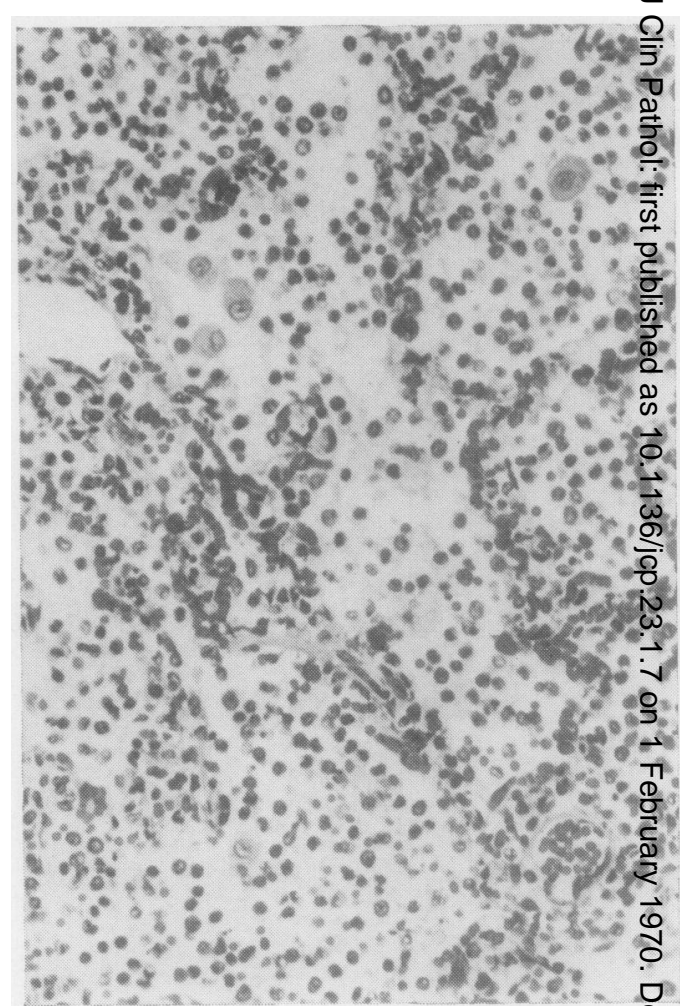

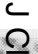

Fig. 9

Fig. 10 


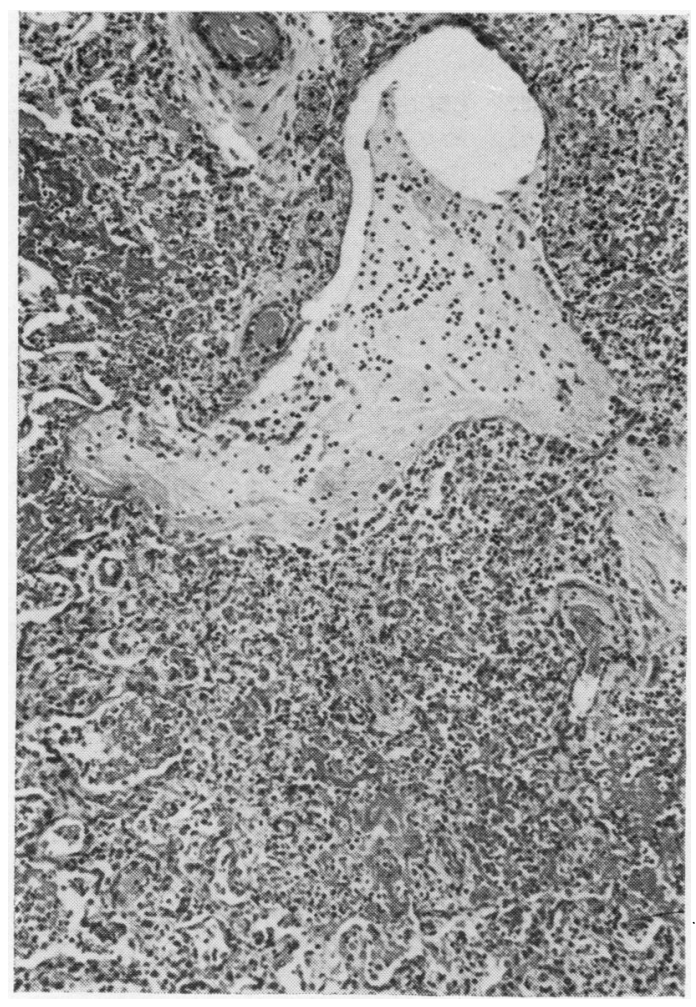

Fig. 12

Fig. 9 Peribronchiolar lymphocytic infiltration, extending into surrounding alveolar walls, accompanied by alveolar exudate. Appearances intermediate between acute bronchiolitis and interstitial pneumonia. H.E. $\times 70$.

Fig. 10 Intraalveolar exudate containing mainly mononuclear cells. Pneumonia. H.E. $\times 160$.

Fig. 11 Interstitial pneumonia. The mucosa of the bronchiole has been totally destroyed; a slough of cell debris and fibrin occupies the lumen. Alveolar walls contain a mononuclear cell infiltration and are lined by hyaline membranes. Connective tissue is oedematous and lymphocytes are prominent. H.E. $\times 60$.

Fig. 12 Necrosis of lung parenchyma, with fibrin masses in neighbouring alveoli, general lymphocytic and macrophage infiltration, and destruction of epithelium of supplying bronchiole. Interstitial pneumonia. H.E. $\times 70$.

Fig. 13 Thrombus occluding muscular pulmonary arteriole. H.E. $\times 80$.

Fig. 14 Touch preparation showing specific fluorescence for $R S V$ in interstitial pneumonia. Cells containing such particles were profuse in interstitial pneumonia. $\times 5,000$.

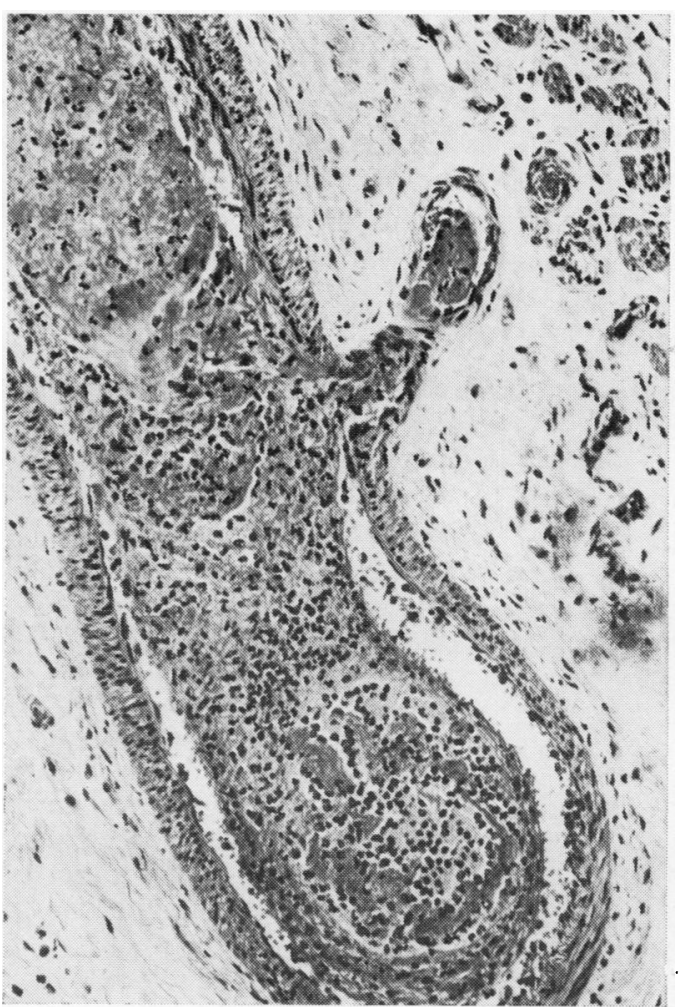

Fig. 13

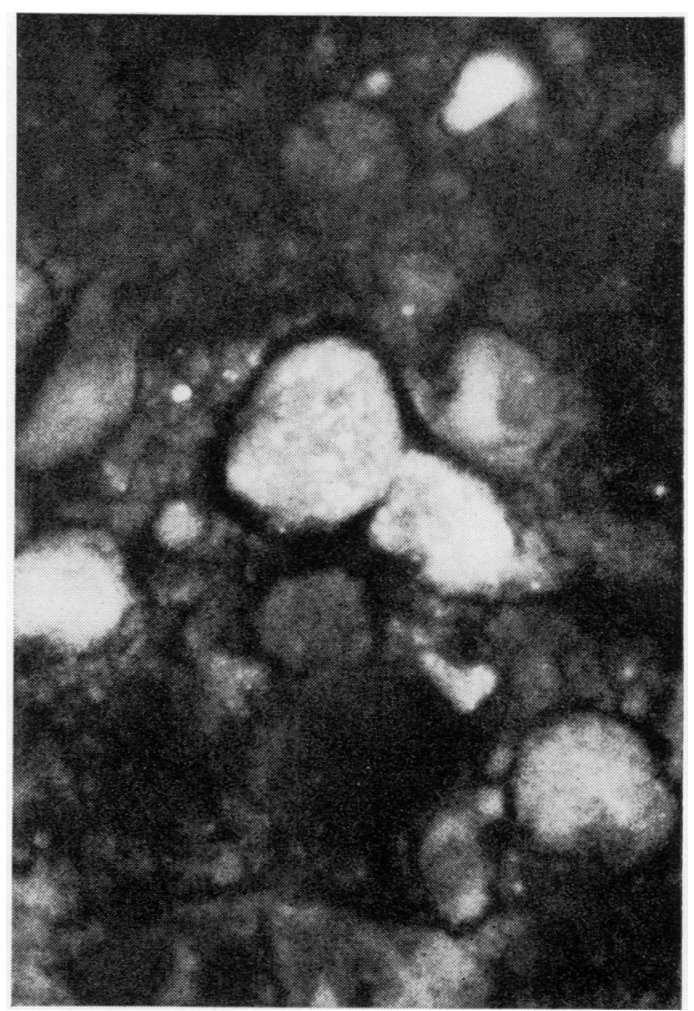

Fig. 14 


\section{Discussion}

Our observations raise three main questions. Do particular viruses induce specific histological changes? Do the histological changes show that acute bronchiolitis and interstitial pneumonia are different diseases, or merely variants of the same tissue response? What are the implications for clinical management?

Becroft (1967) suggested that the histological changes due to infection with adenovirus types 3 and 7 are specific. Our experience does not support this hypothesis: the features of our cases of interstitial pneumonia due to the respiratory syncytial virus, adenovirus type $I$ and parainfluenza type III are all essentially the same. Reynolds (1967) agrees that the respiratory syncytial virus plays a leading role in the aetiology of acute bronchiolitis but describes similar clinical and pathological features due to parainfluenza type III, mycoplasma, and adenovirus infections. The position of the virus inclusion body within the cells may narrow the diagnostic field a little. But in general it seems probable that the host's repertoire of morphological responses is too limited to permit a specific pattern for each virus.

For specific histological diagnosis one may resort to the fluorescent antibody technique. Cohen, Gordon, Rapp, Macauley, and Buckley (1955) made direct comparisons between the development of specific fluorescence and of complement-fixing antigens; they found that the fluorescent antibody procedure seemed the more sensitive of the two methods since it detected antigens earlier. Hers (1963) applied the fluorescent antibody technique to touch preparations of the lung in influenza A infections. Our use of a similar technique in two patients with contrasting respiratory diseases enabled us to make an early and specific postmortem diagnosis of RSV infection. The early results were confirmed in both cases by eventual recovery of the virus in culture. It seems likely that this technique could be used not merely for diagnostic purposes but for mapping the location of the virus in different components of lung tissue.

DO ACUTE BRONCHIOLITIS AND

INTERSTITIAL PNEUMONIA DIFFER IN

KIND OR ONLY IN DEGREE?

The experimental work of McCordock and Muckenfuss (1933) suggests that the morphological differences between acute bronchiolitis and interstitial pneumonia may be due merely to the size of the dose of virus delivered to the lung. These workers injected suspensions of pneumotropic virus intratracheally into rabbits, which were then killed one to five days later. They found that a preparation containing a high concentration of virus produced a pneumonia characterized mainly by haemorrhagic oedema, foci of con- solidation, and irregular areas of necrosis. $\stackrel{C}{\mathbb{Q}}$ more dilute preparation of virus, on the othe hand, caused a mainly proliferative type of lesion; epithelial cells became hyperplastic an the walls of bronchi and bronchioles, and to some extent alveoli, became infiltrated mononuclear cells. This work suggests that human acute bronchiolitis and interstitial pnef monia may not be fundamentally differe diseases, and their contrasting histologic pictures may be merely a function of virus dose and differing immune response of the patiente. An occasional field in our sections of bronchiळ litis suggested a transition to interstitial pneü monia (Fig. 9). Our finding that specificals fluorescing cells were scanty in bronchiolit (case 5) but abundant in pneumonia (case 6) further evidence for this conclusion.

IMPLICATIONS FOR CLINICAL MANAGEMENT

We believe that the study of disordered structu can deepen our understanding of disordere function. The pathological changes in acư् bronchiolitis, for example, suggest that lung function must be embarrassed mainly in mechanical way by the tenacious plugs of mucus and cell debris which so frequently obstruef the smaller bronchioles, and by the increase in residual lung volumes which they bring abouat by trapping air. Treatment should, therefore be directed primarily towards correcting the resulting hypoxia. In spite of the presence polymorphs in some of our cases of bronchi\& litis we found no solid evidence to suggest significant bacterial superinfection.

In interstitial pneumonia the structural chang suggest dysfunction at alveolar level; though bronchial and bronchiolar mucosal necros $\$$ may be severe there is less evidence of obstructive phenomena. The widespread damage to alveolif walls, the hyaline membranes, and the oedema indicate the possibility of a serious ventilation perfusion imbalance with consequent hypox and hypercapnia. The changes also sugge a soil well prepared for secondary bacterif infection. In particular the mucosa, eroded $\vec{Q} 5$ lined by non-ciliated epithelium, and the generas ized alveolar and tissue oedema, would seefi by analogy with influenza to invite bacteria superinfection. But here again there was evidence that secondary bacterial infection had occurred. Perhaps the duration of illness was too short. Clearly this topic, with its implic cations for clinical management, needs much more study.

The application of structural studies to the clinical situation may be difficult. The clinician is faced not with a microscopical section but with a child-a child of a particular age, from particular family, who has developed a respirato illness at a particular time of the year. He begi 
his analysis by observing patterns of symptoms and signs and making a clinical diagnosis; and while some degree of overlap is inevitable the use of carefully defined clinical categories remains the first step in rational management. The consistent use of such categories by the doctor first seeing the child could bring some of the $46 \%$ dying at home into hospital in time. In hospital the clinical category can be more closely defined by radiology, virology, bacteriology, and biochemistry. The structural changes described in this paper will be reflected in the first or serial chest films, and with a fluorescent antibody technique the presence of respiratory syncytial virus can be established within 24 hours of admission in $95 \%$ of infected children. These observations, added to the age of the child, the season of the year, and the clinical features, will enable a diagnosis of acute bronchiolitis (cases 1-5) to be made in many children. They are then treated in ways which will correct the hypoxia, but without antibiotics. A problem arises when radiographic shadows are also present which are described as 'pneumonia'. In our view these are as likely to be due to foci of collapsed parenchyma or to zones of alveolar necrosis as to bacterial pneumonic consolidation. The clinical problem is even greater with interstitial pneumonia. Without lung puncture, which we have not considered justified, a firm clinical distinction cannot be made. This means that when a child with clinical bronchiolitis has 'radiological pneumonia', in addition to primary measures to correct hypoxia and associated metabolic disturbance, we still use antibiotics. This is an interim approach until facilities for the rapid diagnosis of respiratory virus infections are more uniformly available. Early knowledge of the identity of the infecting virus, and the lack of evidence, except in influenza, that the commonly assumed secondary bacterial invasion actually occurs is the justification for our policy of withholding antibiotics in bronchiolitis. We know that the majority of pneumonias, certainly the majority of lethal pneumonias, are of virus origin.

In the past we have assumed that any substantial pneumonic shadow on the radiograph implies the possibility of bacterial infection and therefore justifies the use of antibiotics. But increasing precision in our knowledge of the structural changes in the virus pneumonias should lead to greater precision in the interpretation of the $x$-ray shadows which reflect them. One of the main objectives of our work in this field is to seek a closer correlation between radiological appearances and pathological changes. The morphological findings presented in this paper suggest that bronchiolitis and interstitial pneumonia are degrees or variants of a particular pathological response to virus infection. Since we know that RSV and the parainfluenza viruses are very rarely carried by uninfected children their identification in material from pharyngeal aspirates early in the illness, combined with the radiological appearances of peribronchial thickening or interstitial pneumonia, could lead to a further reduction in the use of antibiotics and provide that increase in diagnostic precision which will be required when antiviral agents are available.

Because of the rarity of RSV in uninfected children our recovery of the virus from three of five cases of the cot death syndrome is intriguing. There was no histological evidence of established tissue response, but the possibility of hypersensitivity suggests a hypothesis which might be tested. The normal antibody response to mucosal replication is probably mucosal IgA. Chanock (1968) has suggested that circulating IgG may form cytotoxic antigen-antibody complexes bound to mucosal cells. A phenomenon of this kind might provide a mechanism for a rapid and severe hypersensitivity reaction.

It is unlikely that acute bronchiolitis leads to any permanent alteration in the bronchial tree, though some follow-up studies (Wittig and Glaser, 1959; Eisen and Bacal, 1963; Hyde and Saed, 1966) suggest an increased incidence of bronchial asthma in later childhood. But it is possible that interstitial virus pneumonia, in which components of the bronchial and bronchiolar walls may be severely damaged, could lead to eventual bronchiectasis. It is believed (Spencer, 1962) that twothirds of all cases of Whitwell's follicular bronchiectasis occur after measles or whooping cough. Slowly accumulating evidence suggests that in certain circumstances adenovirus infections, and perhaps RSV infections, also may lead to similar lasting damage.

Our thanks are due to Professor A. G. Heppleston for advice and comment during the preparation of this paper, to Miss Patricia Sturdy, B.Sc., for help with some aspects of the study, to Miss Dorothy Kitchener, Mr Michael Stones and Mr Albert Young for the photographs, to Mrs Joan Rayson for preparing the typescript, and to the Medical Research Council and the Scientific and Research Subcommittee of the Royal Victoria Infirmary for their support.

References

Andrew, J. D., and Gardner, P. S. (1963). Occurrence of respiratory syncytial virus in acute respiratory disease in infancy. Brit med. $J, 2,1447-1448$.

Becroft, D. M. O. (1967). Histopathology of fatal adenovirus infection of the respiratory tract in young children. J. clin. Path., 20, 561-569.

Beem, M., Wright, F. H., Hamre, D., Egerer, R., and Oehme, M. (1960). Association of chimpanzee coryza agent with acute respiratory disease in children. New Engl. J. Med., 263, 523-530.

Chanock, R. M. (1968). Session of the Gustav Stern Symposium on Perspectives in Virology, New York.

Chanock, R. M., Kim, H. W., Vargosko, A. J., Deleva, A., Johnson, K. M., Cumming, C., and Parrott, R. H. (1961). Respiratory syncytial virus. 1 . Virus recovery and other observations during 1960 outbreak of bronchiolitis, pneumonia and minor respiratory diseases in children. J. Amer. med. Ass., 176, 647-653.

Cohen, S. M., Gordon, I., Rapp, F., Macauley, J. C., and Buckley, S. M. (1955). Fluorescent antibody and complement 
fixation tests of agents isolated in tissue culture from measles patients. Proc. Soc. exp. Biol. (N.Y.), 90, 118-122.

Crone, P. B., Heycock, J. B., Noble, T. C., and Patton, J. B(1964). Serological evidence of infection by respiratory syncytial virus in outbreak of acute bronchiolitis. Brit. med. J., 1, 1539-1540.

Eisen, A. H., and Bacal, H. L. (1963). The relationship of acute bronchiolit is to bronchial asthma. A 4-to-14 year follow-up. Pediatrics, 31, 859-860.

Elderkin, F. M., Gardner, P. S., Turk, D. C., and White, A. C. (1965). Aetiology and management of bronchiolitis and pneumonia in childhood. Brit. med. J., 2, $722-727$.

Gardner, P. S. and McQuillin, J. (1968). Application of immunofluorescent antibody technique in rapid diagnosis of respiratory syncytial virus infection. Brit. med. J., 3, 340-343.

Gardner, P. S., Turk, D. C., Aherne, W. A., Bird, T., Holdaway, M. D., and Court, S. D. M. (1967). Deaths associated with respiratory tract infection in childhood. Brit. med. J., 4,316-320.

Gardner, P. S., McQuillin, J., and Court, S. D. M. (1970). Speculution on pathogenesis in death from respiratory syncytical virus infections. Brit. med. J., in the press.

General Register Office. (1967). Registrar General's Statistical Review of England and Wales for 1966. H.M.S.O., London.

Hers, J. F. Ph. (1963). Fluorescent antibody technique in respiratory viral diseases. Amer. Rev. resp. Dis., 88, Suppl., 316-338.

Holzel, A., Parker, L., Patterson, W. H., White, L. L. R., Thompson, K. M., and Tobin, J. O'H. (1963). The isolation of respiratory syncytial virus from children with acute respiratory disease. Lancet, 1, 295-298.

Hubble, D., and Osborne, G. R. (1941). Acute bronchiolitis in children. Brit. med.J., 1, 107-110.

Hyde, J. S., and Saed, A. M. (1966). Acute bronchiolitis and the asthmatic child. J. Asthma Res., 4, 137-154.

Jackson, C., and Jackson, C. L. (1934). Bronchoscopy, Esophagoscopy and Gastroscopy, p. 160, Saunders, Philadelphia. (Quoted by D. Hubble, and G. R. Osborne.)

McCordock, H. A., and Muckenfuss, R. S. (1933). Similarity of virus pneumonia in animals to epidemic influenza and interstitial broncho-pneumonia in man. Amer. J. Path., 9, 221-252.
McLean, K. H. (1956). The pathology of acute bronchiolitis a study of its evolution. Part I. The exudative plasse. Aust. Ann. Med., 5, 254-267.

Morison, J. E. (1955). Pneumonia and interstitial inflammation of the lung. Lancet, 2, 941-944.

Reynolds, E. O. R. (1967). Bronchiolitis. In Disorders of he Respiratory Tract in Children, edited by E. L. Kencig. Saunders, Philadelphia.

Spencer, H. (1962). Pathology of the Lung, p. 81. Pergaomion Press, Oxford.

Wittig, H. J., and Glaser, J. (1959). The relationship between bronchiolitis and childhood asthma. J. Allergy, 19-23. 